\title{
Impact of reduced emissions on direct and indirect aerosol radiative forcing during COVID-19 lockdown in Europe
}

Simon F. Reifenberg ${ }^{1, \mathrm{a}}$, Anna Martin ${ }^{1}$, Matthias Kohl ${ }^{1}$, Zaneta Hamryszczak ${ }^{1}$, Ivan Tadic ${ }^{1}$, Lenard Röder ${ }^{1}$, Daniel J. Crowley ${ }^{1}$, Horst Fischer ${ }^{1}$, Katharina Kaiser ${ }^{2}$, Johannes Schneider ${ }^{2}$, Raphael Dörich ${ }^{1}$, John N. Crowley ${ }^{1}$, Laura Tomsche ${ }^{3}$, Andreas Marsing ${ }^{3}$, Christiane Voigt ${ }^{3,4}$, Andreas Zahn ${ }^{5}$, Christopher Pöhlker ${ }^{6}$, Bruna A. Holanda ${ }^{6}$, Ovid Krüger ${ }^{6}$, Ulrich Pöschl ${ }^{6}$, Mira Pöhlker ${ }^{6,7,8}$, Patrick Jöckel ${ }^{3}$, Marcel Dorf ${ }^{1}$, Ulrich Schumann ${ }^{3}$, Jonathan Williams ${ }^{1}$, Joachim Curtius $^{9}$, Hardwig Harder ${ }^{1}$, Hans Schlager ${ }^{3}$, Jos Lelieveld ${ }^{1,10}$, and Andrea Pozzer ${ }^{1}$

${ }^{1}$ Max Planck Institute for Chemistry, Atmospheric Chemistry Department, 55128 Mainz, Germany

${ }^{2}$ Max Planck Institute for Chemistry, Particle Chemistry Department, 55128 Mainz, Germany

${ }^{3}$ Deutsches Zentrum für Luft- und Raumfahrt, Institute for Atmospheric Physics, Oberpfaffenhofen, 82230 Wessling, Germany

${ }^{4}$ Johannes Gutenberg-University Mainz, Institute for Physics of the Atmosphere, 55099 Mainz, Germany

${ }^{5}$ Institute of Meteorology and Climate Research, Karlsruhe Institute of Technology, 76344 Karlsruhe, Germany

${ }^{6}$ Max Planck Institute for Chemistry, Multiphase Chemistry Department, 55128 Mainz, Germany

${ }^{7}$ Faculty of Physics and Earth Sciences, Leipzig Institute for Meteorology, University of Leipzig, 04318 Leipzig, Germany

${ }^{8}$ Experimental Aerosol and Cloud Microphysics Department, Leibniz Institute for Tropospheric Research,04318 Leipzig, Germany

${ }^{9}$ Goethe-University of Frankfurt, Institute for Atmospheric and Environmental Sciences, 60438 Frankfurt am Main, Germany

${ }^{10}$ The Cyprus Institute, Climate and Atmosphere Research Center, Nicosia, 1645, Cyprus

${ }^{a}$ now at: MARUM - Center for Marine Environmental Science, University of Bremen, Bremen, Germany

Correspondence: Andrea Pozzer (andrea.pozzer@mpic.de)

\section{Abstract.}

Aerosols influence the Earth's energy balance through direct radiative effects and indirectly by altering the cloud microphysics. Anthropogenic aerosol emissions dropped considerably when the global COVID-19 pandemic resulted in severe restraints on mobility, production, and public life in spring 2020. Here we assess the effects of these reduced emissions on direct and indirect aerosol radiative forcing over Europe, excluding contributions from contrails. We simulate the atmospheric composition with the ECHAM5/MESSy Atmospheric Chemistry (EMAC) model in a baseline (business as usual) and a reduced emission scenario. The model results are compared to aircraft observations from the BLUESKY aircraft campaign performed in May/June 2020 over Europe. The model agrees well with most of the observations, except for sulfur dioxide, particulate sulfate and nitrate in the upper troposphere, likely due to a somewhat biased representation of stratospheric aerosol chemistry and missing information about volcanic eruptions which could have influenced the campaign. The comparison with a business as usual scenario shows that the largest relative differences for tracers and aerosols are found in the upper troposphere, around the aircraft cruise altitude, due to the reduced aircraft emissions, while the largest absolute changes are present at the surface. We also find an increase in shortwave radiation of $0.327 \pm 0.105 \mathrm{Wm}^{-2}$ at the surface in Europe for May 2020, solely attributable to the direct aerosol effect, which is dominated by decreased aerosol scattering of sunlight, followed by reduced 

crease in shortwave radiation from aerosol indirect effects was found to be much smaller than its variability. Impacts on ice crystal- and cloud droplet number concentrations and effective crystal radii are found to be negligible.

\section{Introduction}

Aerosols play a pivotal role in both air pollution and climate change. They cause millions of years of lost life expectancy per year globally (Lelieveld et al., 2015, 2020), impose a negative (net) effective radiative forcing (Bellouin et al., 2020), and are a large source of uncertainty in climate change assessments. A reduction of the cooling effect by a decreased aerosol burden necessitates stronger reductions of greenhouse gases (GHGs) for a targeted net radiative forcing (Larson and Portmann, 2019).

Owing to the central importance of aerosol particles, the reduced emissions resulting from drastic restrictions on mobility, industry and public life during the COVID-19 "lockdowns" in early 2020 (here referred to as "lockdown") (Barré et al., 2020; Evangeliou et al., 2021; Guevara et al., 2021; Le Quéré et al., 2020) sparked a plethora of publications on the subsequent effects on local, regional, and global air pollution (see, for instance, He et al., 2020; Liu et al., 2020; Petetin et al., 2020; Tobías et al., 2020; Venter et al., 2020; Mertens et al., 2021) and climatic effects, on which we will focus in this work.

We recognise that reduced emissions during lockdown do not necessarily translate into improved air quality, as primary pollutants take part in a complex set of chemical processes, which need to be included in a thorough analysis (Kroll et al., 2020). For instance, although ozone was reported to be reduced in the free troposphere in the northern hemisphere (Steinbrecht et al., 2021), the reduced emissions of the nitrogen oxides $\mathrm{NO}$ and $\mathrm{NO}_{2}$ led to an increase in ozone concentrations in urban locations, as an important short-term sink (reaction with NO) was reduced (e.g. Gkatzelis et al., 2021; Sicard et al., 2020; Mertens et al., 2021). This illustrates how the complex (photo-)chemistry and the nonlinearity of the underlying chemical system have to be described and analyzed within the framework of a dynamic atmospheric chemistry model. A chemistry climate model with appropriate chemistry furthermore enables a direct comparison of business as usual and reduced emissions within the same synoptic background conditions, complementary to a purely observation-based approach. Such model investigations are most effective when accompanied and guided by observational data, as will be done in the present study.

The interaction of aerosols with radiation and their climatic impact can be categorized into two types: (i) direct effects by impact on radiation fluxes, and (ii) indirect effects through changes in cloud physical and optical properties. The direct effects include absorption and scattering of electromagnetic waves, whereby aerosol particles, most prominently black carbon (BC), absorb incoming solar radiation, which leads to warming of the ambient air and decreases solar irradiance in the layers below. In addition, aerosols scatter incident radiation back to space, leading to a net cooling of the climate system on average. These processes depend on the size, shape and chemical composition of the aerosols and on the wavelength of the radiation. In addition, the net effect depends on the surface albedo (Yoon et al., 2019; Bellouin et al., 2020).

The reduced emissions in spring 2020 are thus expected to affect aerosol radiative forcing. A reduction in the backscattering of solar radiation is expected to result in warming, which is offset by the anticipated cooling effect through a reduction of black carbon emissions, and the net effect may vary vertically and horizontally. For instance, Gettelman et al. (2021) reported 


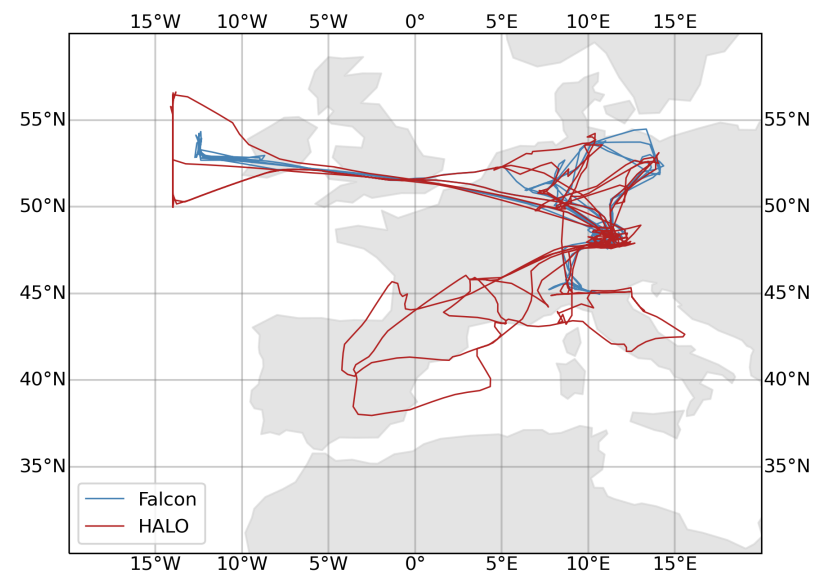

Figure 1. Tracks of conducted flights during the BLUESKY campaign (16th May to 9th June 2020). Colors denote the aircraft, Falcon (blue) and HALO (red).

a simulated net warming at the surface and in the lower troposphere in most regions, caused by enhanced insolation at the surface, and cooling in upper layers of the troposphere, due to reduced absorption by black carbon. They also determined a difference in the clear sky net shortwave (SW) flux at the top of the atmosphere (TOA) of up to $0.1 \mathrm{Wm}^{-2}$ globally in May between simulations with and without reduced emissions, i.e. less outgoing SW radiation due to the lockdown. Complementing the analyses regarding these more immediate effects, Forster et al. (2020) estimate a short-term warming driven by a weakened aerosol cooling through reduced sulfur dioxide $\left(\mathrm{SO}_{2}\right)$ emissions, followed by a cooling of $0.010 \pm 0.005 \mathrm{~K}$ by 2030 in reference to a baseline scenario.

In addition to the aerosol direct effects on the radiation budget, aerosol particles can trigger several indirect effects. Aerosol particles serve as cloud condensation nuclei and thus alter cloud properties, such as cloud albedo, cloud droplet number concentration, formation processes, precipitation and cloud lifetime (see, for instance, Bellouin et al., 2020; Christensen et al., 2020; Lohmann and Feichter, 2005; Twomey, 1959). In turn, clouds also affect aerosols. Clouds convert precursor gases into aerosol particles through heterogeneous chemistry (Ervens et al., 2011; Lelieveld and Heintzenberg, 1992; McMurry and Wilson, 1983) and, at the same time, remove aerosols and soluble gases from the atmosphere by precipitation ("wet deposition").

Clouds are classified based on their liquid water or ice content, since these characteristics determine the efficiency of reflection of solar radiation back to space (cloud albedo effect) and the absorption rate of longwave radiation (greenhouse effect), thus their impact on the Earth's radiation budget. Clouds consisting only of ice crystals (e.g. cirrus clouds) occur mostly in high altitudes at temperatures below the homogeneous freezing threshold of $\sim-35^{\circ} \mathrm{C}$ (Pruppacher and Klett, 1997; Kärcher and Seifert, 2016; Bacer et al., 2021). Ice crystals (ICs) are formed either due to homogeneous or heterogeneous freezing depending on aerosol characteristics and number concentration, temperature, supersaturation and vertical air motion (Pruppacher and Klett, 1997). IC number densities in cirrus clouds are typically lower (Voigt et al., 2017) compared to clouds at lower altitude, and cirrus clouds are often optically thin and transmit shortwave radiation and absorb longwave radiation, resulting in 
an overall positive net radiative effect at the TOA (Bacer et al., 2018, 2021; Gasparini et al., 2017). In contrast, mixed-phase clouds, consisting of ICs and cloud droplets, form only due to heterogeneous nucleation at lower altitudes and temperatures higher than $-35^{\circ} \mathrm{C}$. These optically thick clouds reflect a comparably large amount of the incoming SW radiation, leading to a negative net radiative effect at the TOA (Chen et al., 2000). The cloud albedo effect can be enhanced by the Twomey effect (Twomey, 1959), whereby high number concentrations of CCN lead to a higher number of droplets of smaller size compared to clouds formed with lower number of CCN. Accordingly, clouds, containing more droplets of smaller sizes, reflect solar radiation more strongly than clouds containing fewer droplets of larger size. This effect is especially important over the ocean, where the number of natural CCNs, compared to anthropogenic CCNs, is much lower than over land (Lohmann and Feichter, 2005). Ship emissions, including aerosol particles, create clouds with a much higher reflectivity (or albedo) than clouds formed by the less numerous natural CCNs outside of the ship tracks (Platnick et al., 2000). The same effect arises in aircraft flight tracks, where the emitted particles may act as ice nucleating particles, leading to contrail formation (Schumann et al., 2017) and an increase in cirrus cloud formation in the upper troposphere (Boucher, 1999). Still, the magnitude of the aviation soot effect on the radiation budget remains uncertain (Urbanek et al., 2018; Righi et al., 2021). Recently, satellite data have been used to quantify changes in clouds in regions with COVID-reduced airtraffic in 2020 (Quaas et al., 2021; Gettelman et al., 2021). With respect to contrails, Schumann et al. (2021a, b) find a substantial reduction of contrail cirrus optical thickness and radiative forcing during the lockdown period.

The modification of cloud cover resulting from differing particle number concentrations has further effects on the lifetime of a cloud. An increase in smaller cloud particles makes the clouds more persistent and delays the occurrence of precipitation (referred to as cloud lifetime effect, Lohmann and Feichter, 2005). Increased cloud lifetime affects not only the timing but also the location of precipitation. The increased lifetime of clouds also extends the period over which a cloud can reflect radiation, thus adding to the Twomey effect. With increasing aerosol number concentration corresponding to a negative perturbation of the radiation budget, both effects contribute to cooling at the surface and at the TOA (Lohmann and Feichter, 2005). The number and size distribution of cloud nucleating particles can thus affect the extent of transmission of radiation.

Using an observation-guided model, the COVID-19 lockdown provided an opportunity to examine how the climate system reacts to perturbations such as abruptly reduced air pollution emissions. The COVID-19 lockdown may also serve to assess the impact of economic recovery with respect to climate change mitigation: for instance, Forster et al. (2020) show that investments aimed at a "green" opposed to a fossil-fueled recovery can reduce projected warming by $0.3 \mathrm{~K}$ by 2050 , with only negligible contributions from the lockdown.

In the present study, we simulate the chemical composition of the atmosphere in Europe in spring 2020 under a reduced emission scenario and a business as usual scenario with a state-of-the-art climate and chemistry simulation system, constraining atmospheric dynamics by reanalysis meteorological data. We use a unique observational data set of trace gases and aerosols obtained during an aircraft measurement campaign in Europe during the COVID-19 lockdown in summer 2020 to evaluate the model results. We then quantify the effects of the lockdown on radiative transfer in the atmosphere, particularly the change in shortwave fluxes and shortwave heating rates attributable to a reduced aerosol burden in Europe. Furthermore, we examine the 
impacts of the lockdown scenario on cloud properties, including potential changes of the radiative forcing caused by indirect aerosol effects.

This paper is structured as follows. In Sect. 2 we describe the model together with an overview of the simulations performed (Sect. 2.1), as well as the observational data (Sect. 2.2). The model evaluation is presented in Sect. 3. We then investigate the impacts of the reduced emissions during the 2020 COVID-19 lockdown on direct aerosol effects and indirect cloud-aerosol effects (Sect. 4).

\section{Data and methods}

\subsection{Model data}

The ECHAM5/MESSy Atmospheric Chemistry (EMAC) model is a numerical chemistry and climate simulation system that includes submodels describing tropospheric and middle atmospheric processes and their interaction with oceans, land and human influences (Jöckel et al., 2016). It uses the second version of the Modular Earth Submodel System (MESSy2) to link multi-institutional computer codes. The core atmospheric model is the 5th generation European Centre Hamburg general circulation model (ECHAM5, Roeckner et al., 2006).

For the present study we applied EMAC (ECHAM5 version 5.3.02, MESSy version 2.55.0) in T63L47MA-resolution, i.e. with a spherical truncation of T63 (corresponding to a quadratic Gaussian grid of approx. 1.8 by 1.8 degrees in latitude and longitude) with 47 vertical hybrid pressure levels up to $1 \mathrm{~Pa}$. Roughly 22 levels are included in the troposphere. The dynamics of the EMAC model has been weakly nudged (Jeuken et al., 1996; Jöckel et al., 2006) towards the ERA-interim meteorological reanalysis data (Berrisford et al., 2011) of the European Centre for Medium-Range Weather Forecasts (ECMWF) to represent the actual day to day meteorology in the troposphere.

The setup of the chemistry submodels for this study is similar to the one presented by Jöckel et al. (2016, simulation RC1aero-07), but with the addition of the submodel ORACLE (Tsimpidi et al., 2014) for the organic chemistry calculation and with stratospheric heterogeneous chemistry neglected. Initial conditions for the meteorology were also taken from the ERA-interim reanalysis data, while the ones for the chemical composition were from previous EMAC simulations (Pozzer et al., 2021). In addition, the anthropogenic emissions used are based on CAMS-GLOB-ANTv4.2 (Granier et al., 2019). To reproduce the effect of lockdown on the emissions, we adopted the reduction coefficient for Europe as in Guevara et al. (2021) for the sectors of energy production (ENE), road transport (TRO) and industrial processes (IND). The reduced emissions were averaged for the period 19th April to 26th of April (i.e. last available week in the dataset), and applied (for each country) for March, April, May and June. For aviation (AVI) we adopted the same method, although we applied the estimated factor to the entire aviation emissions, without any country distinction.

The aerosol-cloud interactions are based on the aerosol microphysics parameterization of Pringle et al. (2010) including aerosol aging and the continuous calculation of aerosol number concentration depending on the mass mixing ratio and mixing state. Additionally, cloud formation processes are accounted for using the convection framework of Tost et al. (2006) based on the convection calculation schemes of Tiedtke (1989) and Nordeng (1994). Large-scale cloud formations and prognostic 
variables depending on cloud microphysical processes follow the work of Lohmann et al. (2007); Lohmann and Hoose (2009); Bacer et al. (2018). Thereby, the ice crystal number concentration (ICNC) formation in the cirrus regime ( $T \leq 238.15 \mathrm{~K})$ was modified according to Neubauer et al. (2019) to reduce the artificial homogeneous freezing of dry aerosol particles independent of availability of water vapor.

We performed four simulations, all covering the period from January 2019 to July 2020:

- STD : standard (i.e. "business as usual") emissions, without cloud-aerosol interaction,

- RED : reduced emissions due to lockdown, without cloud-aerosol interaction,

- STDCLOUD : like STD but with aerosol-cloud interaction,

- REDCLOUD : like RED but with aerosol-cloud interaction.

In all simulations performed, the impact of different aerosol concentrations on the radiation (discussed in Sect. 4.2.1) is diagnosed but not used by the general circulation model, which instead adopts an aerosol climatology (Pringle et al., 2010). Similarly, changes in the tracers (e.g. ozone) do not influence the radiation, which is calculated with a greenhouse gases climatology.

The model evaluation is performed with the RED simulation, while its difference with the STD simulation is used to evaluate the impact of the reduced emissions during the lockdown. Simulation RED and STD have binary identical dynamics (Deckert et al., 2011), as no feedback between chemistry and dynamic is present. Differently, in REDCLOUD and STDCLOUD, the aerosol-cloud interaction is activated following the work of Lohmann and Hoose (2009); Bacer et al. (2018), leading to modification of cloud properties and therefore to changes in radiation and dynamics. The simulations REDCLOUD and STDCLOUD are only used for estimating the indirect effects of aerosols (see Sect. 4.2.2).

\subsection{BLUESKY observational data}

We compare simulated trace gas and aerosol abundances to a comprehensive set of observations obtained during the BLUESKY campaign (Voigt et al., 2021), led by the German Aerospace Center (DLR) and the Max Planck Institute for Chemistry (MPIC), with the aim of investigating the effects of reduced emissions on atmospheric chemistry and physics. From 16th May to 9th June 2020 in situ measurements of trace gases and trace particles were conducted in the atmosphere over European urban areas and the North Atlantic flight corridor with the High Altitude and Long Range (HALO) research aircraft and a second research aircraft, Falcon (see Fig. 1 for flight paths). In total 8 and 12 flights were conducted with the HALO and the Falcon, respectively.

We compare aerosol mass concentrations of black carbon (BC, size range between 70 and $500 \mathrm{~nm})$, sulfate $\left(\mathrm{SO}_{4}^{2-}\right)$, nitrate $\left(\mathrm{NO}_{3}^{-}\right)$, ammonium $\left(\mathrm{NH}_{4}^{+}\right)$, organic aerosol particles (ORG, all from 40 to $800 \mathrm{~nm}$ ) and aerosol particle number concentrations (between $250 \mathrm{~nm}$ to $40 \mu \mathrm{m})$. These are complemented by volume mixing ratios of carbon monoxide $(\mathrm{CO})$, ozone $\left(\mathrm{O}_{3}\right)$, nitric oxide (NO), hydrogen peroxide $\left(\mathrm{H}_{2} \mathrm{O}_{2}\right)$, peroxyacetyl nitrate $(\mathrm{PAN})$, nitric acid $\left(\mathrm{HNO}_{3}\right)$, and sulfur dioxide $\left(\mathrm{SO}_{2}\right)$. Details regarding instrumentation are provided by Voigt et al. (2021). We additionally use air temperature $T$, wind speed and specific 
humidity $q$ to assess the quality of the reproduced synoptic conditions which are constrained (nudged) in the model. For the comparison, the model output was sampled online in space and time by the submodel S4D (Jöckel et al., 2016), following the flight tracks of the field campaign and with a time frequency of 5 minutes.

\section{Results: Model evaluation}

A summary of the comparison of observations and model results is listed in Table 1 and presented graphically in Figs. 2 and 3.

The ambient air temperature $T$ is reproduced very well by the model; the average ratio of observed and simulated $T$ is equal to 1.00 with a normalized root mean squared error of 0.04 (NRMSE; RMSE divided by range of observations). The vertical temperature profile is matched in the lower and free troposphere with a slight underestimation of observed temperatures towards the upper troposphere (Fig. 2). Specific humidity $q$ is also captured reasonably well in the model, (NRMSE $=0.06$ ), as $85.9 \%$ of simulated values lie within a factor of two of the observations, yet slightly overestimated (see Fig. 2 and Table 1). In addition, horizontal wind speed $\left\|\boldsymbol{u}_{h}\right\|$ is also reproduced accurately with a low NRMSE (0.06) and an average ratio of 1.02.

Overall, the agreement between the meteorological variables from model and observations indicates successful initialization and nudging of meteorological variables and that the meteorological conditions during the relevant time period are simulated adequately. As the model is not nudged in the stratosphere or boundary layer (the nudging coefficient is maximal in the free troposphere (Jöckel et al., 2006)), the slight underestimation of temperature in the upper troposphere region is not surprising. Nevertheless, the temperature bias is much lower than in other EMAC studies, despite the use of same nudging method and coefficients (Jöckel et al., 2016), due to the intialization and shorter simulation time in this work. As temperature and humidity are important quantities regarding cloud formation, and accurate wind vectors are key for representing advective processes, the following analyses of atmospheric composition and the effects on radiative transfer build on an accurate representation of the meteorological state of the model.

\subsection{Trace gases}

Observed ozone $\left(\mathrm{O}_{3}\right)$ mixing ratios are reproduced well by the model. More than $94 \%$ of simulated values are within a factor of 2 of the observations ("PF2" value), the normalized root mean squared error of 0.04 is low. Nevertheless, the model seems to slightly overestimate the observations, as already pointed out in various studies (e.g. Jöckel et al., 2016).

Simulated carbon monoxide (CO) mixing ratios are also in a good agreement with the observations, and virtually all simulated values lie within a factor of two of the observations. However, especially at lower altitudes, the simulated mixing ratios somewhat underestimate the observed values, although the difference between average observations and average model results are well within their respective variability, and the shape of the vertical profile is qualitatively well reproduced. The same holds for nitric oxide (NO), which exhibits a C-shaped profile. The NRMSE for NO is low (0.08) and the average ratio of simulated to observed mixing ratio is 0.99 , however more than a third of simulated values deviate more than a factor of two from the observations, due to the high variability of this tracer. Particularly the range of the observed mixing ratios close to the surface 

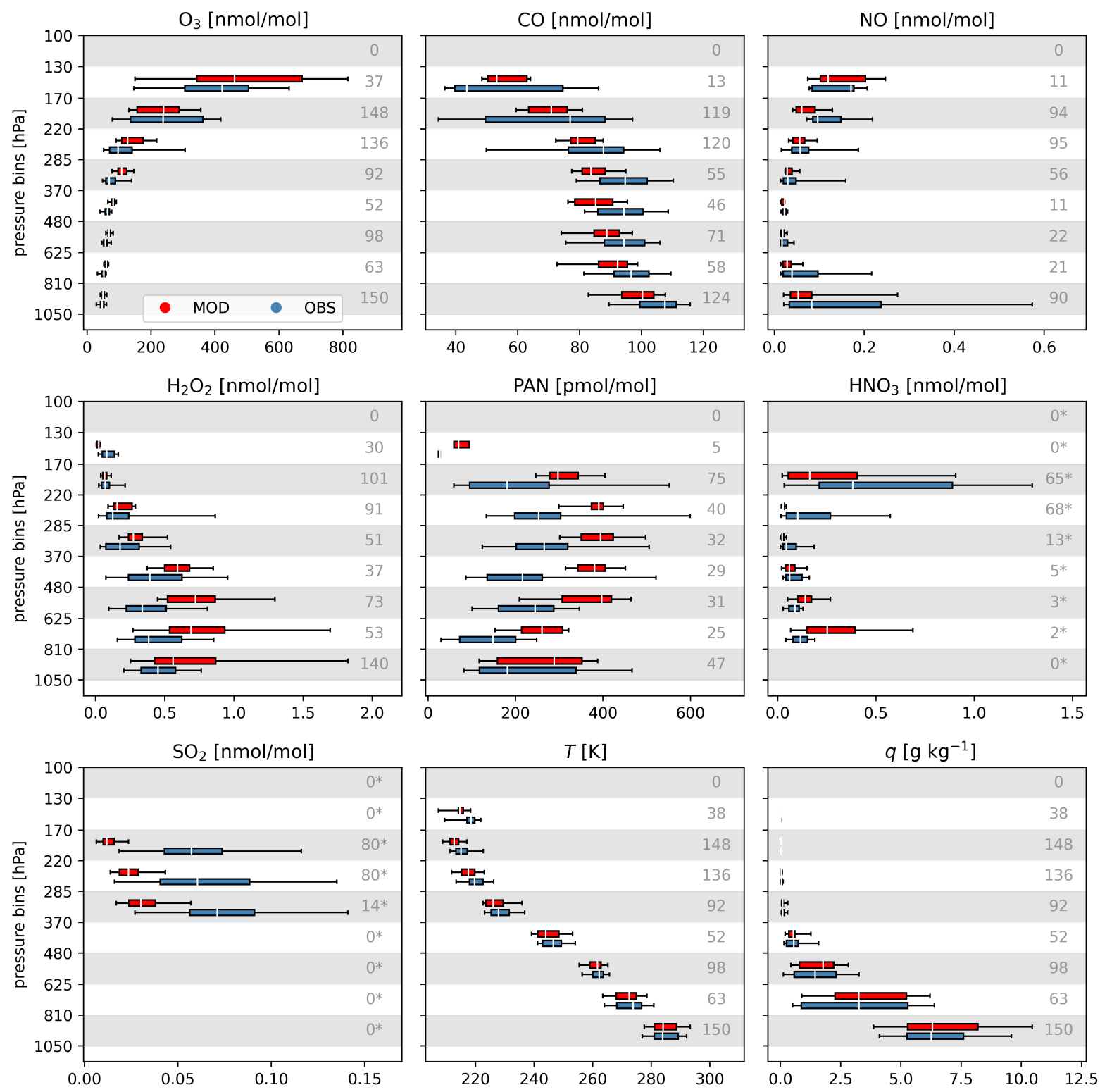

Figure 2. Vertical distribution of simulated (red, "MOD") and observed (blue, "OBS") tracer mixing ratios and two meteorological variables ( $T$ and $q$ ), represented by box-whisker plots for pressure bins. The white line marks the median, the box corresponds to lower and upper quartiles, the whiskers represent the 5-95 percentile. The grey numbers on the right indicate the sample size (number of observed and interpolated simulated data points) for each pressure bin. Simulated values are from the RED simulation, i.e. with reduced emissions and no aerosol-cloud interactions. For $\mathrm{HNO}_{3}$ and $\mathrm{SO}_{2}$ (measured onboard of the Falcon aircraft, grey number marked with asterisks) the domain average of the model results over Europe at the corresponding altitude were used, not the values sampled online on the flight track. 
is not well reproduced by the model, which results from the short lifetime of NO and the challenge in reproducing its local variation by a global model.

Hydrogen peroxide $\left(\mathrm{H}_{2} \mathrm{O}_{2}\right)$ and peroxyacetyl nitrate (PAN) are less well represented, the average ratios of simulated to observed mixing ratio (2.01 for $\mathrm{H}_{2} \mathrm{O}_{2}$ and 1.91 for PAN) indicate an overestimation by the model. Nevertheless, for both species about two thirds of the simulated points are still within a factor of two of the observations (see Fig. 2), and the measured dependence on altitude is captured by the model.

Sulfur dioxide $\left(\mathrm{SO}_{2}\right)$ was sampled predominantly at high altitudes between 370 to $170 \mathrm{hPa}$, where it is strongly underestimated by the model. We hypothesize that the systematic underestimation of $\mathrm{SO}_{2}$ concentrations is due to an inaccurate representation of transport from the boundary layer or from the stratosphere to the upper troposphere or due to model shortcomings within the stratospheric aerosol chemistry, which will be discussed briefly as part of the following Sect. 3.2. All in all, as summarized in Table 1, there is reasonable agreement between observed and simulated mixing ratios of the trace gases investigated.

\subsection{Aerosols}

The vertical profile of the aerosol number concentration is qualitatively reproduced (see Fig. 3). In the lowest altitude pressure bin, the range and median of the observations and model results match very well. There are some deviations between 850 and $480 \mathrm{hPa}$, where simulated number concentrations are larger than the observed ones, although this overestimation is well within the observations' variability. This overestimation dominates the average ratio of modeled to measured values (2.60, see Table 1).

The measured black carbon (BC) concentrations are captured well by the model close to the surface, while the observational variability is underestimated at high altitudes. The NRMSE of 0.09 is relatively low, as the higher abundance closer to the surface - that is, closer to the sources - is well represented, both in terms of magnitude and variability.

Sulfate $\left(\mathrm{SO}_{4}^{2-}\right)$ exhibits qualitatively similar features as $\mathrm{BC}$; the relatively high concentrations observed in the lower troposphere are matched by the simulated concentrations, yet there is a significant underestimation of sulfate aerosol concentrations in the upper troposphere. We hypothesize that the modeled underestimation of sulfur species is related to missing contribution of volcanic eruptions that have reached the stratosphere at low latitudes and return to the troposphere at higher latitude. Many small and medium size eruptions have been reported in the year prior to the BLUESKY campaign (https://volcano.si.edu, last access 30. October 2021), but their influence on the upper troposphere and lower stratosphere is yet to be quantified. Some preliminary test simulations are mentioned below.

Between 1050 and $625 \mathrm{hPa}$ simulated organic aerosol concentrations are somewhat larger in the model than in reality, the shape of the vertical profile is, however, qualitatively reproduced.

Nitrate $\left(\mathrm{NO}_{3}^{-}\right)$and ammonium $\left(\mathrm{NH}_{4}^{+}\right)$concentrations close to the surface are generally well reproduced. While, at higher altitudes, the simulated $\mathrm{NH}_{4}^{+}$agrees with the observations, simulated nitrate is too high, which is probably related to the co-located underestimation of sulfate. 
Table 1. Summary of model-observations comparison. The same spatio-temporal location were used for all simultaneously available points . NRMSE shows the root mean squared error normalized by the range of the observations. PF2 denotes the percentage of model points within a factor of 2 of the observations. The column $\overline{\mathrm{MOD} / \mathrm{OBS}}$ is the average of the simulated and observed data ratios.

\begin{tabular}{llcc}
\hline Variable & NRMSE & PF2 & $\overline{\text { MOD/OBS }}$ \\
\hline Trace gases & & & \\
$\mathrm{O}_{3}$ & 0.04 & 94.7 & 1.25 \\
$\mathrm{CO}$ & 0.14 & 99.3 & 0.98 \\
$\mathrm{NO}$ & 0.08 & 65.0 & 0.99 \\
$\mathrm{H}_{2} \mathrm{O}_{2}$ & 0.32 & 61.5 & 2.01 \\
$\mathrm{PAN}$ & 0.13 & 60.3 & 1.91 \\
$\mathrm{HNO}_{3}$ & 0.37 & 12.9 & 0.46 \\
$\mathrm{SO}_{2}$ & 0.40 & 25.9 & 0.43 \\
\hline Aerosols & & & \\
$\mathrm{BC}$ & 0.09 & 18.6 & 0.68 \\
$\mathrm{NO}_{3}^{-}$ & 0.14 & 20.6 & 0.92 \\
$\mathrm{NH}_{4}^{+}$ & 0.22 & 28.8 & 0.83 \\
$\mathrm{SO}_{4}^{2-}$ & 0.16 & 26.8 & 0.72 \\
Organics & 0.45 & 40.6 & 1.73 \\
Number conc. & 0.11 & 42.8 & 2.60 \\
\hline Meteorology & & & \\
$T$ & 0.04 & 100.0 & 1.00 \\
$q$ & 0.06 & 85.9 & 1.27 \\
$\left\|\boldsymbol{u}_{h}\right\|$ & 0.06 & 100.0 & 1.02 \\
\hline & & &
\end{tabular}

The results of the model/measurement comparison are summarised in Table 1. We conclude that there is generally reasonable agreement between simulated and observed trace gases and aerosols with some deviation of the aerosol concentrations, especially in the mid-upper troposphere.

A single factor causing the model underestimation of $\mathrm{BC}$ and sulfate aerosol concentrations in the upper troposphere, e.g. a localized plume of pollution, is judged unlikely, as $\mathrm{BC}_{\text {and }} \mathrm{SO}_{4}^{2-}$ do not correlate $(r<0.01, p=0.90)$ : in fact, mapping observed $\mathrm{SO}_{4}^{2-}$ concentrations to ozone (a tracer of stratospheric air), and carbon monoxide (a tracer of tropospheric air), reveals that high $\mathrm{SO}_{4}^{2-}$ concentrations coincide with high ozone $(r=0.83, p<0.01)$ and low carbon monoxide $(r=-0.65, p<0.01)$ (Fig. 4). A similar, yet weaker, correspondence can be found in the simulated data (see Fig. 4). This suggests a stratospheric source of sulfate aerosols in both model and reality, although stratospheric sulfate aerosol appears to be represented poorly in the model. It is noteworthy that a precursor for sulfate aerosols, sulfur dioxide, is also systematically underestimated. We 

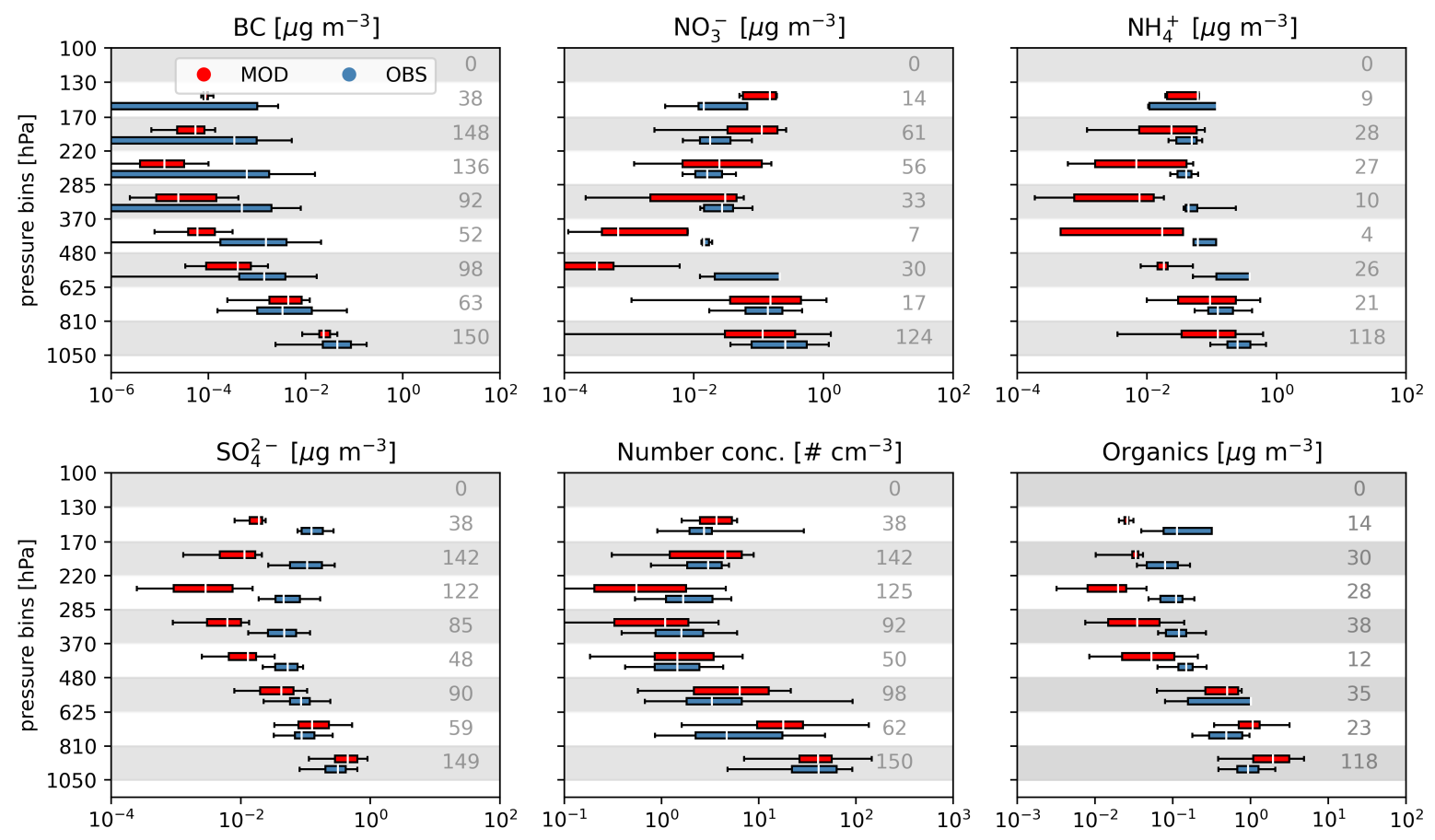

Figure 3. As Fig. 2, but for aerosols. Please note the logarithmic scale in the x-axis.
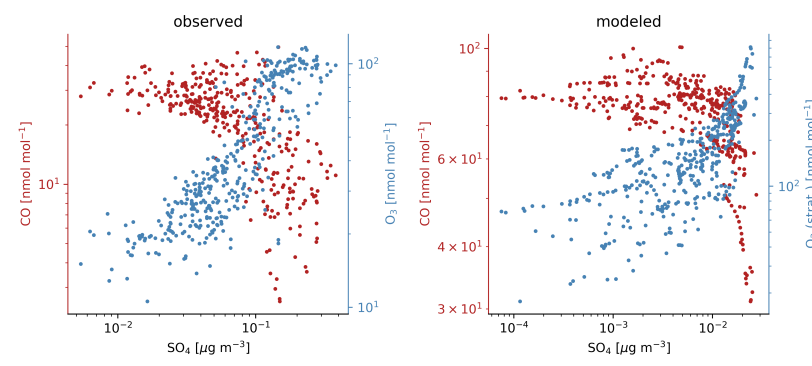

Figure 4. Scatter plot of co-located $\mathrm{SO}_{4}$ and $\mathrm{CO}$ (red) respective $\mathrm{O}_{3}$ (blue) abundance between 350 and $150 \mathrm{hPa}$ from observations (left) and the RED simulation (right).

assume that the high $\mathrm{SO}_{2}$ abundance measured is of volcanic origin. We tested this by injecting high levels of $\mathrm{SO}_{2}$ in the stratosphere in additional simulations, mimicking volcanic eruptions at Raikoke (June) and Ulawun (June and August) in 2019 (see de Leeuw et al., 2021; Kloss et al., 2021). However, this did not affect the concentrations of $\mathrm{SO}_{4}^{2-}$ and $\mathrm{NO}_{3}^{-}$significantly (not shown). A partial increase of $\mathrm{SO}_{4}^{2-}$ was obtained by including the volcanic eruption of Taal in January 2020. Nevertheless this is still not enough to bring the model results close to the observations. We therefore conclude that our observed underestimation of $\mathrm{SO}_{4}^{2-}$ is of stratospheric origin, although it is not fully clear what caused it. 
A further partition of the region of interest into three subregions (Central Europe, Southern Europe, Atlantic) did not reveal substantial spatial dependencies of model deviation from observations (not shown).

\section{Results: Impact of reduced emissions}

To quantify the effect of the lockdown, we use the business as usual simulations (STD and STDCLOUD) in the analyses. We focus on May 2020, as this time period is covered by the measurement campaign and the atmosphere can be expected to have adjusted to the impact of abruptly reduced emissions. We also analyse the impact in an area encompassing Europe (the region of study), i.e. over a longitude-latitude box from -20 to $20^{\circ} \mathrm{E}$ and 30 to $60^{\circ} \mathrm{N}$ (exactly the depicted map sector in Fig. 1).

\subsection{Impact on tracers and aerosols}

As no feedback between chemistry and dynamics is activated in the RED and STD simulations, any differences between these simulations are purely attributable to the different emissions during the lockdown and the consequent different chemical regimes.

In general, while large absolute changes are expected at the surface, in the upper troposphere (UT) we find the largest relative changes, due to the strong influence of the local emissions and to the low mixing ratios of most of the species investigated (see Fig. 5). Large relative changes in the UT are found for $\mathrm{NO}, \mathrm{SO}_{2}$ and $\mathrm{BC}$, with a strong reduction $(\sim 50 \%$ or more $)$ in the region between 200 and $300 \mathrm{hPa}$, i.e. the typical aircraft cruise altitude. The reduced air traffic during the lockdown period greatly decreased the emissions of nitrogen oxides into the UT, and the effects of the lockdown on other tracers in the UT are mostly a result of this strong reduction. Hydroxyl radicals (OH) decrease by roughly $20 \%$ in the UT and $5 \%$ elsewhere in the troposphere, a direct effect of a reduced $\mathrm{OH}$ recycling by $\mathrm{NO}_{\mathrm{x}}$. Despite the reduced $\mathrm{OH}$, carbon monoxide does not increase, due to the decrease in the direct emissions. The overall effect of the lockdown for most tracer is a combination of reduced emissions and reduced sinks (i.e. oxidation via $\mathrm{OH}$ ): while this is well balanced for $\mathrm{CO}$ (changes in the order of few percent), for $\mathrm{SO}_{2}$ the emission reductions are larger than the decrease in the reaction with $\mathrm{OH}$, causing its mixing ratio to be reduced (up to $50 \%$ in the UT) compared to the business as usual scenario. It must be stressed however, that those relative changes in the upper troposphere, although significant, have a very minor impact on most trace gas budgets, due to their low mixing ratios at these altitudes.

Similar to the trace gases, for most aerosols the lockdown reduces their concentration mostly at the surface, although the largest relative differences are simulated in the UT, due to the low concentration at these altitudes. For example, sulfate is subject to a large relative change in the UT but to much larger absolute changes close to the surface, mimicking the changes in $\mathrm{SO}_{2}$ (see also Fig. 6). Furthermore, $\mathrm{BC}$ decreases significantly in the whole troposphere, due to the strong reduction of the emissions both at the surface and in the UT (from aircraft). The aerosol reductions during the lockdown have implications on the incoming shortwave radiation, as discussed in the next section. 

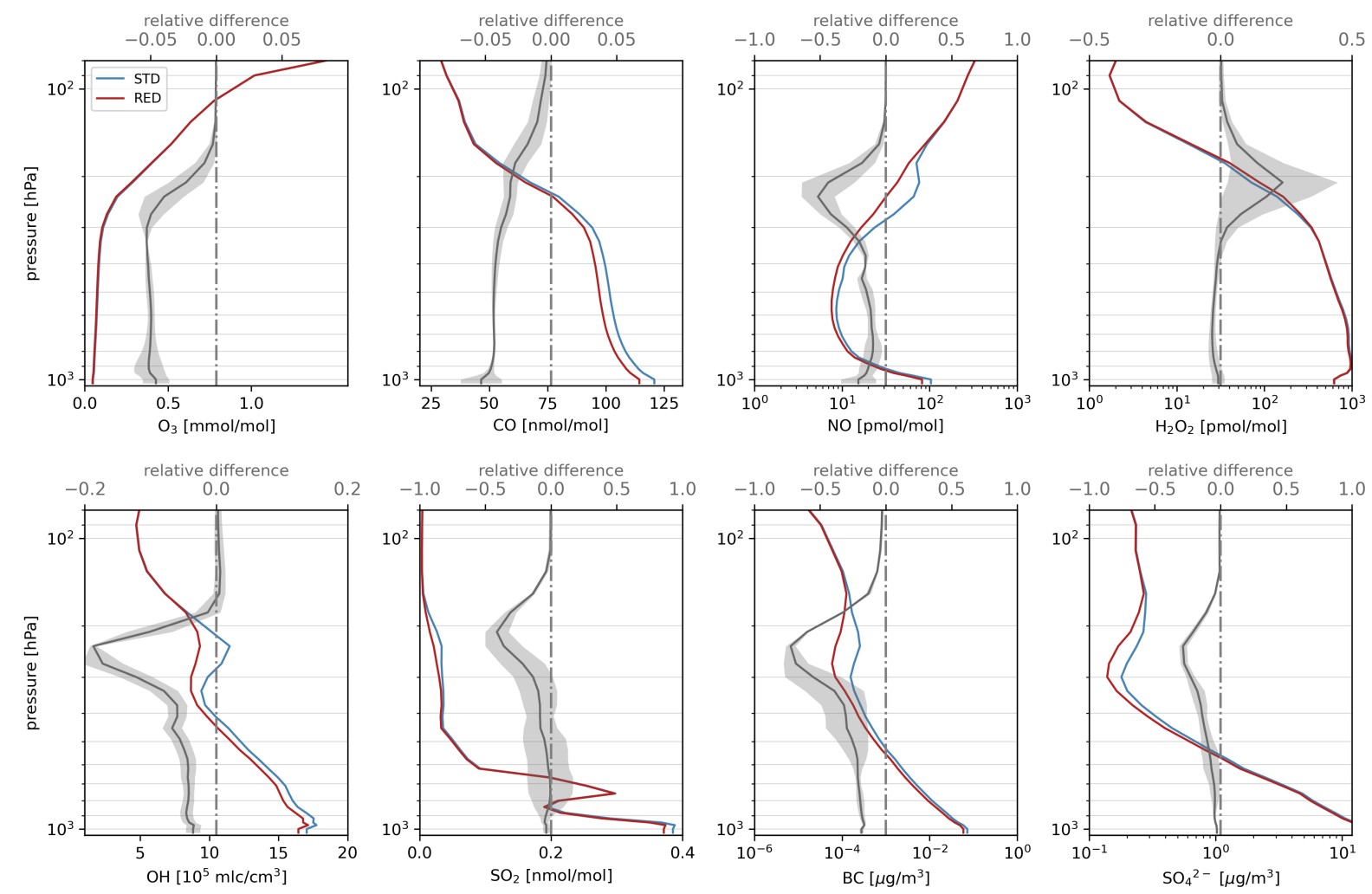

Figure 5. Vertical profiles from STD and RED simulations and their relative difference ((RED-STD)/STD). The grey area represents one standard deviation of the spatial-temporal mean (grey line). Please note the different scales for the relative differences.

\subsection{Impact on radiation}

As the model is nudged (i.e. constrained air temperature with prescribed sea surface temperatures), we do not investigate any effects on the outgoing longwave radiation. Rather, we focus the analyses on the shortwave flux $F_{\mathrm{SW}}$ and its induced heating rate $(\partial T / \partial t)_{\mathrm{SW}}$ in the area encompassing Europe.

\subsubsection{Direct effects}

Aerosols directly impact the radiation balance by absorption and scattering of electromagnetic waves. Compared to the business as usual emissions, the monthly mean sulfate (and inorganic aerosols, not shown) and black carbon concentrations are reduced most strongly close to the surface, with another (much smaller) local maximum close to the commercial flight level (around $200 \mathrm{hPa}$, see also Fig. 6). Furthermore, the mean aerosol (number) concentrations were reduced in the lockdown scenario throughout the whole air column (see Fig. 8 and Sect. 4.2.2), with the reduction being most pronounced between 300 and 200 $\mathrm{hPa}$, likely due to reduced aircraft emissions and the effect on particle formation and coagulation at these altitudes. 
We calculate the simulated difference in the downwelling shortwave flux between simulation RED and STD, i.e. the impact of the reduced emissions on the SW radiation. Here only the aerosol contribution is estimated, removing any radiative effect from changes in trace gases (e.g. ozone) within the Europe longitude-latitude box for May 2020. The differences are largest over continental central Europe and lowest over Northern Scandinavia (Fig. 7), with no large spatial gradients over Europe. In virtually all regions there is more downwelling shortwave radiation in the reduced emission scenario. Spatially averaged at ground level within the European domain, there is an increase of $0.327 \pm 0.105 \mathrm{Wm}^{-2}$ under clear sky condition (i.e., no clouds) compared to the baseline scenario, while at the TOA the increase is $0.198 \pm 0.092 \mathrm{Wm}^{-2}$. This increase, together with the reduced heating rates of ambient air, is indicative of a reduction in shortwave scattering and absorption, due to the reduced inorganic aerosol and black carbon concentrations, i.e. the lockdown contributed to make the atmosphere more transparent to SW radiation. We also compared our results with Van Heerwaarden et al. (2021): our radiative effect of all aerosols in our RED simulation for May is of $-3.33 \pm 1.36 \mathrm{Wm}^{-2}$, which is close to their value of $-2.3 \mathrm{Wm}^{-2}$. The column integrated contribution of backscatter and absorption can be estimated from the radiation values at TOA and surface, indicating that, during lockdown, the total backscatter (clear sky) of SW radiation has been decreased by $0.263 \pm 0.070 \mathrm{Wm}^{-2}$, while the total absorption (clear sky) was decreased by $0.064 \pm 0.053 \mathrm{Wm}^{-2}$, with slightly more than one third of this caused by the BC decrease. Reduced scattering by aerosol particles plays a larger role, as the "net" (i.e. the difference attributable to the lockdown) shortwave flux is positive in the whole air column; on the other hand, reduced absorption dominates the shortwave component of direct aerosol effects in the boundary layer, as clearly shown in Fig. 6 . The heating of ambient air exhibits a local minimum in the upper troposphere, which is however small compared to that in the lower troposphere. We calculate the surface integral of the accumulated heating due to shortwave fluxes, only attributable to aerosols under clear sky conditions: the difference in the atmospheric layer directly above the surface is $-0.005 \pm 0.001 \mathrm{~K} /$ day, i.e. less heating of the boundary layer in the lockdown conditions compared to normal emissions. The decreased heating (for the entire column but mostly

310 at the surface) is due to the reduced absorption by BC during the lockdown conditions, causing a cooling of the atmosphere (through SW radiation) despite an increase of the incoming radiation. Both the changes in heating and shortwave flux are solely attributable to the different aerosol burden in the STD and RED simulations.

\subsubsection{Aerosol-cloud interactions}

In Fig. 8, the vertical distributions of the aerosol number concentration (N), ice crystal number concentration (ICNC), cloud droplet number concentration (CDNC) and ice crystal radius $(r)$ are shown for Europe for both simulations, STDCLOUD and REDCLOUD. Additionally, the SW flux at the TOA and the surface have been calculated from these coupled aerosolcloud simulations (see Table 2), both for the total effect (i.e. direct plus indirect) and for the indirect (i.e. neglecting any direct radiation influence of the aerosol particles). Due to the short simulation period, the difference between these simulations is much smaller than its variability, represented by its spatial and temporal standard deviation. Nevertheless, comparing the vertical distribution of number concentrations of aerosols, ice crystals and cloud droplets, the largest relative difference between STDCLOUD and REDCLOUD (i.e. the two simulations where the aerosol-cloud feedback is activated) is found for the aerosol number concentration between 200 and $300 \mathrm{hPa}$. These are the cruise altitudes at which the largest aircraft emissions are 

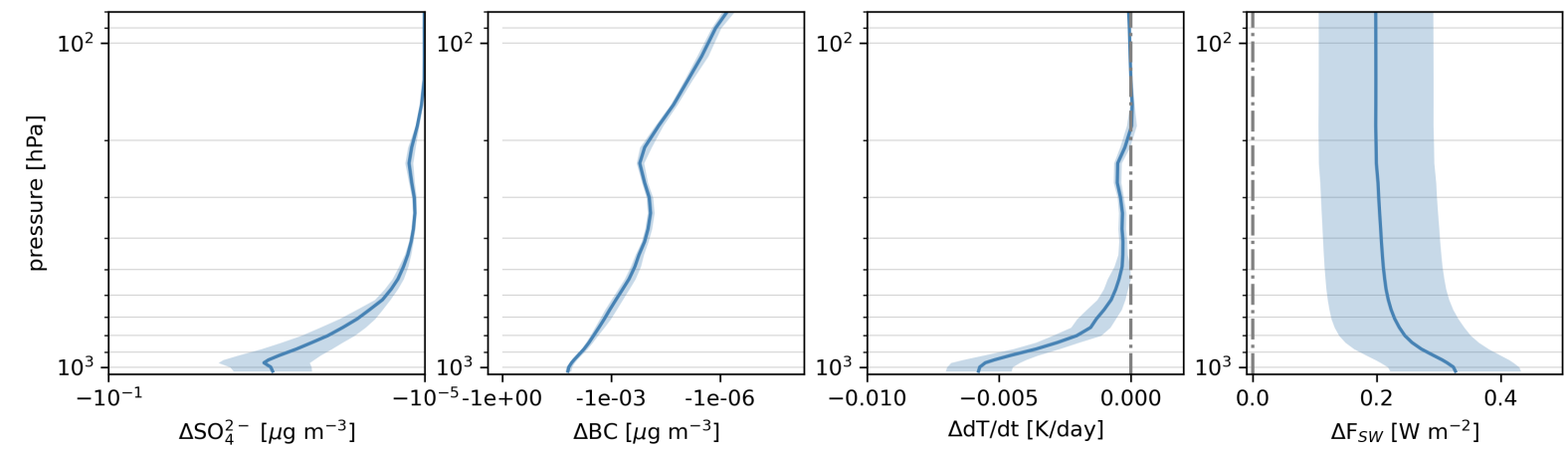

Figure 6. Vertical profiles of the difference of monthly mean sulfate mass concentration $\left(\mathrm{SO}_{4}^{2-}\right)$, black carbon mass concentration (BC), heating rate $(\mathrm{d} T / \mathrm{d} t)$ and the net shortwave flux $\left(F_{\mathrm{SW}}\right)$ between the reduced emission scenario RED and the standard emission scenario STD. shortwave flux and shortwave heating are derived under clear sky conditions. The shading indicates one standard deviation of the monthly mean difference. Note the logarithmic horizontal axis for the two plots on the left.

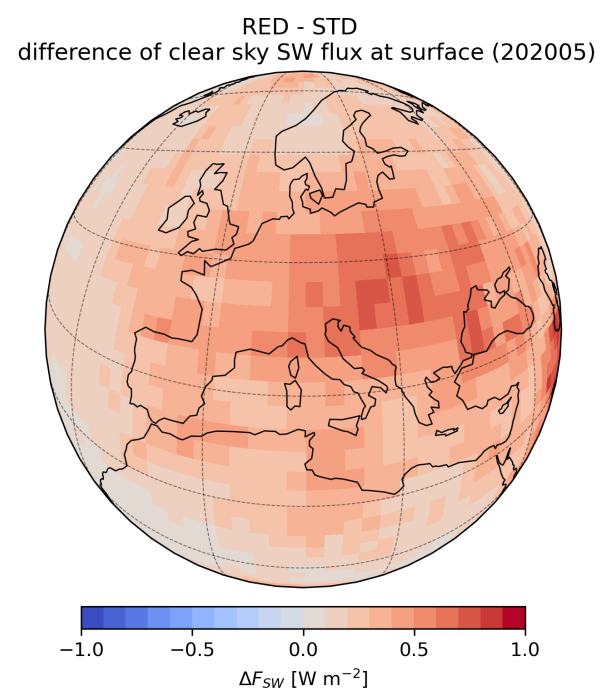

Figure 7. Difference of monthly mean clear sky shortwave radiation (May 2020) at the surface between RED and STD simulation. Positive (red) values indicate more incoming radiation at the surface due to less absorption and backscattering in the "lockdown" atmosphere than in the business as usual scenario. Note that we used a common reduction factor for emissions from countries outside Europe.

injected in the model and therefore these differences can be directly connected to the reduced air traffic present during the lockdown (REDCLOUD). As this altitude is somewhat higher than the typical (cold) cloud altitude, the effect on clouds is less pronounced. At the highest level of these clouds (see Fig. 8) the ICNC are reduced (by $\simeq 30 \%$ at $250 \mathrm{hPa}$, although with large 

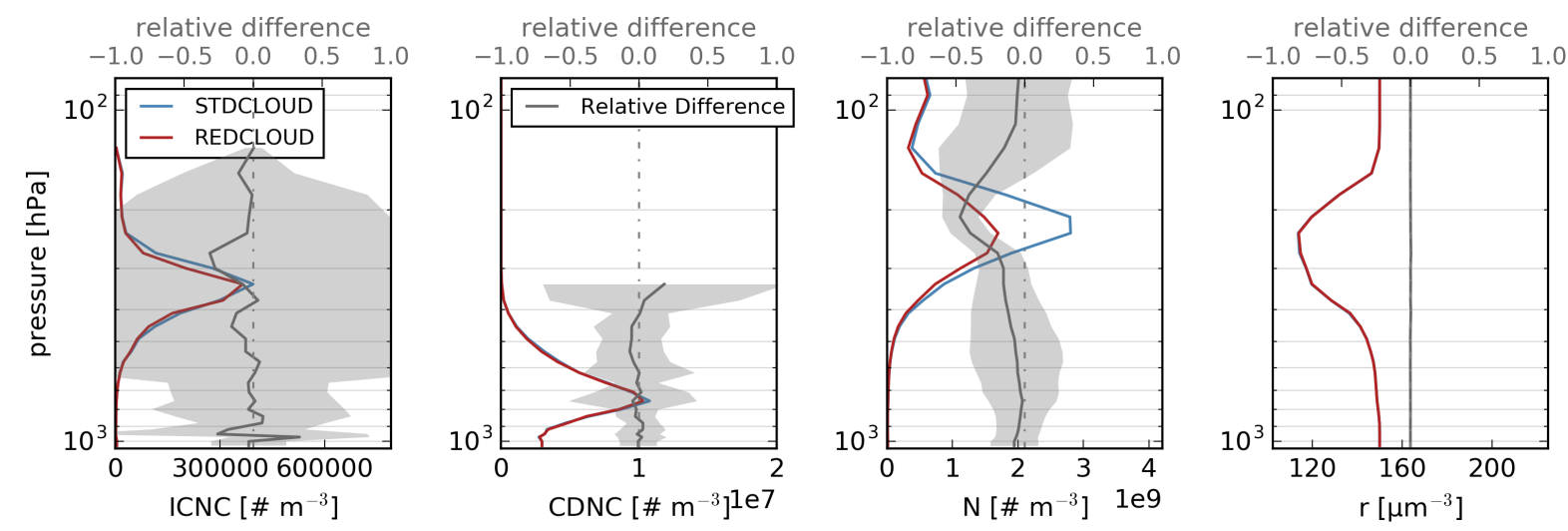

Figure 8. Vertical profiles of the monthly mean ice crystal number concentration (ICNC), cloud droplet number concentration (CDNC), aerosol number concentration $(N)$ and ice crystal effective radius $(r)$ of the reduced emission scenario REDCLOUD (red) and the standard emission scenario STDCLOUD (blue) and their relative difference (grey line) for May 2020 over Europe. The grey area denote the spatial and temporal standard deviation of the relative difference.

variability), while no visible effect is found for CDNC. These results are in line with those obtained by Righi et al. (2021), who showed that aircraft emissions do increase ice crystal number concentration, although their results were not statistically significant. The ice crystal effective radius seems to be the least affected by the reduced emissions during the COVID-19 lockdown, with a negligible absolute and relative difference.

To investigate the effect of reduced aircraft emissions on the SW flux via the indirect aerosol effect at the TOA and surface (SRF), the mean differences in SW flux between REDCLOUD and STDCLOUD for May were calculated over Europe. Positive values indicate greater reflection of SW radiation back to space (for TOA) or more absorption through the troposphere (for surface values) in the STDCLOUD simulation, compared to the REDCLOUD. The mean surface differences are $0.307 \pm 0.115$ $\mathrm{Wm}^{-2}$ for the clear sky and $0.443 \pm 1.063 \mathrm{Wm}^{-2}$ for the all sky case. At the TOA the mean differences in shortwave fluxes are $0.186 \pm 0.106 \mathrm{Wm}^{-2}$ (clear sky) and $0.281 \pm 0.928 \mathrm{Wm}^{-2}$ (all sky, Table 2). We should notice that the clear sky results agree with the direct effect estimated in Sect.4.2.1 but with different simulations, confirming the consistency of the calculations. Thus, the indirect effect of aerosols enhances the direct effect on the SW radiation during the lockdown, even with larger intensity. This confirms the importance of the cloud-aerosol interaction, as mentioned by Hong et al. (2016), Gasparini and Lohmann (2016) and Myhre et al. (2013). However, those values are associated with large standard deviations, related to the strong spatial variability of the upward shortwave radiation difference between the simulations.

\section{Conclusions}

We simulated the effects of drastically reduced anthropogenic emissions on the atmospheric composition in Europe during the COVID-19 lockdown in spring 2020. We evaluated the model simulations with observations obtained during the aircraft 
Table 2. Aerosol direct and indirect effects on the shortwave radiation flux at the top of atmosphere (TOA) and surface (SRF) over Europe for May. Note that direct effects are derived from STD and RED simulations, and indirect and total (i.e. direct plus indirect) effects from STDCLOUD and REDCLOUD. The indirect effect of clear sky estimation is obviously equal to zero, but it was included to confirm the validity of the calculations.

\begin{tabular}{l|c|cc}
\hline & RED-STD & \multicolumn{2}{|c}{ REDCLOUD-STDCLOUD } \\
$\Delta F_{\mathrm{SW}}\left[\mathrm{Wm}^{-2}\right]$ & direct & indirect & total \\
\hline TOA & $0.090 \pm 0.035$ & $0.188 \pm 0.759$ & $0.281 \pm 0.928$ \\
TOA clear sky & $0.198 \pm 0.092$ & $0.000 \pm 0.006$ & $0.186 \pm 0.106$ \\
SRF & $0.209 \pm 0.053$ & $0.233 \pm 1.089$ & $0.443 \pm 1.063$ \\
SRF clear sky & $0.327 \pm 0.105$ & $0.001 \pm 0.023$ & $0.307 \pm 0.115$ \\
\hline
\end{tabular}

measurement campaign BLUESKY. The overall agreement between observations and simulated aerosol concentrations and trace gas mixing ratios is reasonable. Nevertheless, problems remain regarding stratosphere-troposphere transport, especially of volcanic influence, which resulted in systematically underestimated $\mathrm{SO}_{2}$ and $\mathrm{SO}_{4}^{2-}$ of stratospheric origin, and a consequent overestimation of $\mathrm{NO}_{3}^{-}$(which substitutes the underestimated sulfate in ammonium salts) in the upper troposphere.

Focusing on the effects of aerosol particles on the shortwave radiation budget, we find that their reduction due to lockdown leads to a net clear sky SW flux increase of $0.327 \pm 0.105$ and $0.198 \pm 0.092 \mathrm{Wm}^{-2}$ at surface level and TOA over Europe, respectively. The increase of the SW radiation during the lockdown period is due to the decrease of both black carbon and inorganic aerosols, which made the atmosphere more transparent to the incoming solar radiation by reducing SW absorption and SW backscatter, with the latter dominating. It must be stressed that although this BC reduction causes an increase in the SW incoming radiation, the SW heating has also been reduced by up to $0.005 \mathrm{~K} /$ day, due to the lowered BC absorption.

With reduced emissions, the model simulates a lower number concentration of aerosols; this reduction is located at an altitude too high to effectively influence the cold cirrus clouds (aircraft cruising altitude, $\simeq 250 \mathrm{hPa}$ ). The analysis of the indirect aerosol effect did not give any conclusive results, due to the large variability in the calculations caused by the short duration of the lockdown "experiment".

Note that contrails and their contribution to radiative forcing are not considered in this study. Contrails are expected to reduce solar radiation reaching the Earth surface and to reduce outgoing longwave radiation. The mean changes induced by reduced air traffic in 2020 compared to 2019 , computed in two model studies, were of the order of -0.1 to $0.5 \mathrm{Wm}^{-2}$ over Europe (Gettelman et al., 2021; Schumann et al., 2021b), so at a magnitude comparable to the aerosol effects found in this study. We therefore plan to include contrail effects in a forthcoming study.

Code availability. The Modular Earth Submodel System (MESSy) is continuously further developed and applied by a consortium of institutions. The usage of MESSy and access to the source code is licensed to all affiliates of institutions which are members of the MESSy 
https://doi.org/10.5194/acp-2021-1005

Preprint. Discussion started: 10 December 2021

(C) Author(s) 2021. CC BY 4.0 License.

(c) (1)

365 Consortium. Institutions can become a member of the MESSy Consortium by signing the MESSy Memorandum of Understanding. More information can be found on the MESSy Consortium Website (http://www.messy-interface.org). The code presented here has been based on MESSy version 2.55 and is available as git commit \#dcdc3ed8, in the MESSy repository.

Data availability. Data are available from the contact author under request.

Author contributions. A.P. and S.R. planned the research. A.P. and S.R. collected and prepared the emission data. A.M. implemented code corrections for aerosol-cloud interactions. A.P. performed the model simulations. P.J. contributed to the overall model development and helped with the preparation of the model setups. M.K. provided the script for the aerosol mass estimation in the model. Z.H., I.T., L.R., D.J.C. and H.F. provided the data for CO, $\mathrm{NO}$ and $\mathrm{H}_{2} \mathrm{O}_{2}$. J.S. and K.K. provided observational aerosol composition data. R.D. and J.N.C. were responsible for the PAN measurements. C.V., L.T. and A.M. provided observational data of $\mathrm{HNO}_{3}$ and $\mathrm{SO}_{2}$. A.Z. provided the ozone data. O.K., B.H., C.P., M.P. and U.P. were conducting, analyzing and interpreting the BC data. M.D. organized the field campaign logistically.

375 J.C. planned the flight tracks during the campaign. H.S. coordinated the measurements on the FALCON. S.R. and A.P. performed the model evaluation and analysis of direct effects. A.M. and A.P. performed the analysis of indirect effects. U.S. and A.P. discussed the results on the radiative forcing. S.R., A.M and A.P. wrote the manuscript with the help of J.C., M.K. and J.W.. A.P. and J.L. supervised the project. All authors discussed the results and contributed to the review and editing of the manuscript.

Competing interests. The authors declare that they have no conflict of interest. 


\section{References}

Bacer, S., Sullivan, S. C., Karydis, V. A., Barahona, D., Krämer, M., Nenes, A., Tost, H., Tsimpidi, A. P., Lelieveld, J., and Pozzer, A.: Implementation of a comprehensive ice crystal formation parameterization for cirrus and mixed-phase clouds in the EMAC model (based on MESSy 2.53), Geoscientific Model Development, 11, 4021-4041, 2018.

Bacer, S., Sullivan, S. C., Sourdeval, O., Tost, H., Lelieveld, J., and Pozzer, A.: Cold cloud microphysical process rates in a global chemistryclimate model, Atmospheric Chemistry and Physics, 21, 1485-1505, https://doi.org/10.5194/acp-21-1485-2021, 2021.

Barré, J., Petetin, H., Colette, A., Guevara, M., Peuch, V.-H., Rouil, L., Engelen, R., Inness, A., Flemming, J., Pérez García-Pando, C., Bowdalo, D., Meleux, F., Geels, C., Christensen, J. H., Gauss, M., Benedictow, A., Tsyro, S., Friese, E., Struzewska, J., Kaminski, J. W., Douros, J., Timmermans, R., Robertson, L., Adani, M., Jorba, O., Joly, M., and Kouznetsov, R.: Estimating lockdown induced European $\mathrm{NO}_{2}$ changes, Atmospheric Chemistry and Physics Discussions, 2020, 1-28, https://doi.org/10.5194/acp-2020-995, in review, 2020.

Bellouin, N., Quaas, J., Gryspeerdt, E., Kinne, S., Stier, P., Watson-Parris, D., Boucher, O., Carslaw, K. S., Christensen, M., Daniau, A.L., Dufresne, J.-L., Feingold, G., Fiedler, S., Forster, P., Gettelman, A., Haywood, J. M., Lohmann, U., Malavelle, F., Mauritsen, T., McCoy, D. T., Myhre, G., Mülmenstädt, J., Neubauer, D., Possner, A., Rugenstein, M., Sato, Y., Schulz, M., Schwartz, S. E., Sourdeval, O., Storelvmo, T., Toll, V., Winker, D., and Stevens, B.: Bounding Global Aerosol Radiative Forcing of Climate Change, Reviews of Geophysics, 58, e2019RG000 660, https://doi.org/10.1029/2019RG000660, e2019RG000660 10.1029/2019RG000660, 2020.

Berrisford, P., Dee, D., Poli, P., Brugge, R., Fielding, M., Fuentes, M., Kållberg, P., Kobayashi, S., Uppala, S., and Simmons, A.: The ERA-Interim archive Version 2.0, p. 23, https://www.ecmwf.int/node/8174, 2011.

Boucher, O.: Air traffic may increase cirrus cloudiness, Nature, 397, 30-31, https://doi.org/10.1038/16169, number: 6714 Publisher: Nature

Chen, T., Rossow, W. B., and Zhang, Y.: Radiative Effects of Cloud-Type Variations, Journal of Climate, 13, 264-286, https://doi.org/10.1175/1520-0442(2000)013<0264:REOCTV>2.0.CO;2, publisher: American Meteorological Society Section: Journal of Climate, 2000.

Christensen, M. W., Jones, W. K., and Stier, P.: Aerosols enhance cloud lifetime and brightness along the stratus-to-cumulus transition, Proceedings of the National Academy of Sciences, 117, 17 591-17 598, https://doi.org/10.1073/pnas.1921231117, 2020.

de Leeuw, J., Schmidt, A., Witham, C. S., Theys, N., Taylor, I. A., Grainger, R. G., Pope, R. J., Haywood, J., Osborne, M., and Kristiansen, N. I.: The 2019 Raikoke volcanic eruption - Part 1: Dispersion model simulations and satellite retrievals of volcanic sulfur dioxide, Atmospheric Chemistry and Physics, 21, 10 851-10 879, https://doi.org/10.5194/acp-21-10851-2021, 2021.

Deckert, R., Jöckel, P., Grewe, V., Gottschaldt, K.-D., and Hoor, P.: A quasi chemistry-transport model mode for EMAC, Geoscientific Model

Development, 4, 195-206, 2011.

Ervens, B., Turpin, B. J., and Weber, R. J.: Secondary organic aerosol formation in cloud droplets and aqueous particles (aqSOA): a review of laboratory, field and model studies, Atmospheric Chemistry and Physics, 11, 11 069-11 102, https://doi.org/10.5194/acp-11-11069-2011, 2011.

Evangeliou, N., Platt, S. M., Eckhardt, S., Lund Myhre, C., Laj, P., Alados-Arboledas, L., Backman, J., Brem, B. T., Fiebig, M., Flentje, H., Marinoni, A., Pandolfi, M., Yus-Dìez, J., Prats, N., Putaud, J. P., Sellegri, K., Sorribas, M., Eleftheriadis, K., Vratolis, S., Wiedensohler, A., and Stohl, A.: Changes in black carbon emissions over Europe due to COVID-19 lockdowns, Atmospheric Chemistry and Physics, 21, 2675-2692, https://doi.org/10.5194/acp-21-2675-2021, 2021. 
Forster, P. M., Forster, H. I., Evans, M. J., Gidden, M. J., Jones, C. D., Keller, C. A., Lamboll, R. D., Quéré, C. L., Rogelj, J., Rosen, D., Schleussner, C.-F., Richardson, T. B., Smith, C. J., and Turnock, S. T.: Current and future global climate impacts resulting from COVID-19, Nature Climate Change, 10, 913-919, https://doi.org/10.1038/s41558-020-0883-0, 2020.

Gasparini, B. and Lohmann, U.: Why cirrus cloud seeding cannot substantially cool the planet, Journal of Geophysical Research: Atmospheres, 121, 4877-4893, 2016.

Gasparini, B., Münch, S., Poncet, L., Feldmann, M., and Lohmann, U.: Is increasing ice crystal sedimentation velocity in geoengineering simulations a good proxy for cirrus cloud seeding?, Atmospheric Chemistry and Physics, 17, 4871-4885, https://doi.org/10.5194/acp-174871-2017, 2017.

Gettelman, A., Lamboll, R., Bardeen, C. G., Forster, P. M., and Watson-Parris, D.: Climate Impacts of COVID-19 Induced Emission Changes, Geophysical Research Letters, 48, e2020GL091 805, https://doi.org/10.1029/2020GL091805, e2020GL091805 2020 GL091805, 2021.

Gkatzelis, G. I., Gilman, J. B., Brown, S. S., Eskes, H., Gomes, A. R., Lange, A. C., McDonald, B. C., Peischl, J., Petzold, A., Thompson, C. R., and Kiendler-Scharr, A.: The global impacts of COVID-19 lockdowns on urban air pollution: A critical review and recommendations, Elementa: Science of the Anthropocene, 9, https://doi.org/10.1525/elementa.2021.00176, 00176, 2021.

Granier, C., Darras, S., Denier van der Gon, H., Doubalova, J., Elguindi, N., Galle, B., Gauss, M., Guevara, M., Jalkanen, J.-P., Kuenen, J., Liousse, C., Quack, B., Simpson, D., and Sindelarova, K.: The Copernicus Atmosphere Monitoring Service global and regional emissions (April 2019 version), Copernicus Atmosphere Monitoring Service (CAMS) report, https://doi.org/10.24380/d0bn-kx16, 2019.

Guevara, M., Jorba, O., Soret, A., Petetin, H., Bowdalo, D., Serradell, K., Tena, C., Denier van der Gon, H., Kuenen, J., Peuch, V.-H., and Pérez García-Pando, C.: Time-resolved emission reductions for atmospheric chemistry modelling in Europe during the COVID-19 lockdowns, Atmospheric Chemistry and Physics, 21, 773-797, https://doi.org/10.5194/acp-21-773-2021, 2021.

He, G., Pan, Y., and Tanaka, T.: The short-term impacts of COVID-19 lockdown on urban air pollution in China, Nature Sustainability, 3, 1005-1011, https://doi.org/10.1038/s41893-020-0581-y, 2020.

Hong, Y., Liu, G., and Li, J.-L.: Assessing the radiative effects of global ice clouds based on CloudSat and CALIPSO measurements, Journal of Climate, 29, 7651-7674, 2016.

Jeuken, A., Siegmund, P., Heijboer, L., Feichter, J., and Bengtsson, L.: On the potential assimilating meteorological analyses in a global model for the purpose of model validation, J. Geophys. Res., 101, 16939-16950, 1996.

Jöckel, P., Tost, H., Pozzer, A., Brühl, C., Bucholz, J., L., G., Hoor, P., Kerkweg, A., Lawrence, M., Sander, R., Steil, B., Stiller, G., Tanarhte, M., Taraborrelli, D., van Aardenne, J., and Lelieveld, J.: Evaluation of the atmospheric chemistry GCM ECHAM5/MESSy: Consistent simulation of ozone in the stratosphere and troposphere, Atmos. Chem. Phys., 6, 5067-5104, 2006.

Jöckel, P., Tost, H., Pozzer, A., Kunze, M., Kirner, O., Brenninkmeijer, C. A. M., Brinkop, S., Cai, D. S., Dyroff, C., Eckstein, J., Frank, F., Garny, H., Gottschaldt, K.-D., Graf, P., Grewe, V., Kerkweg, A., Kern, B., Matthes, S., Mertens, M., Meul, S., Neumaier, M., Nützel, M., Oberländer-Hayn, S., Ruhnke, R., Runde, T., Sander, R., Scharffe, D., and Zahn, A.: Earth System Chemistry integrated Modelling (ESCiMo) with the Modular Earth Submodel System (MESSy) version 2.51, Geoscientific Model Development, 9, 1153-1200, https://doi.org/10.5194/gmd-9-1153-2016, 2016.

Kärcher, B. and Seifert, A.: On homogeneous ice formation in liquid clouds, Quarterly Journal of the Royal Meteorological Society, 142, 1320-1334, 2016.

Kloss, C., Berthet, G., Sellitto, P., Ploeger, F., Taha, G., Tidiga, M., Eremenko, M., Bossolasco, A., Jégou, F., Renard, J.-B., and Legras, B.: Stratospheric aerosol layer perturbation caused by the 2019 Raikoke and Ulawun eruptions and their radiative forcing, Atmospheric Chemistry and Physics, 21, 535-560, https://doi.org/10.5194/acp-21-535-2021, 2021. 
Kroll, J. H., Heald, C. L., Cappa, C. D., Farmer, D. K., Fry, J. L., Murphy, J. G., and Steiner, A. L.: The complex chemical effects of COVID-19 shutdowns on air quality, Nature Sustainability, 12, 777-779, https://doi.org/10.1038/s41557-020-0535-z, 2020.

Larson, E. J. L. and Portmann, R. W.: Anthropogenic aerosol drives uncertainty in future climate mitigation efforts, Scientific Reports, 9, 16 538, https://doi.org/10.1038/s41598-019-52901-3, 2019.

Le Quéré, C., Jackson, R. B., Jones, M. W., Smith, A. J. P., Abernethy, S., Andrew, R. M., De-Gol, Anthony J. Willis, D. R., Shan, Y., Canadell, J. G., Friedlingstein, P., Creutzig, F., and Peters, G. P.: Temporary reduction in daily global CO 2 emissions during the COVID19 forced confinement, Nature Climate Change, 10, 647-653, https://doi.org/10.1038/s41558-020-0797-x, 2020.

Lelieveld, J. and Heintzenberg, J.: Sulfate cooling effect on climate through in-cloud oxidation of anthropogenic SO2, Science, 258, 117-120, 1992.

Lelieveld, J., Evans, J. S., Fnais, M., Giannadaki, D., and Pozzer, A.: The contribution of outdoor air pollution sources to premature mortality on a global scale, Nature, 525, 367-371, https://doi.org/10.1038/nature15371, 2015.

Lelieveld, J., Pozzer, A., Pöschl, U., Fnais, M., Haines, A., and Münzel, T.: Loss of life expectancy from air pollution compared to other risk factors: a worldwide perspective, Cardiovascular Research, 116, 1910-1917, https://doi.org/10.1093/cvr/cvaa025, 2020.

Liu, F., Page, A., Strode, S. A., Yoshida, Y., Choi, S., Zheng, B., Lamsal, L. N., Li, C., Krotkov, N. A., Eskes, H., van der A, R., Veefkind, P., Levelt, P. F., Hauser, O. P., and Joiner, J.: Abrupt decline in tropospheric nitrogen dioxide over China after the outbreak of COVID-19, Science Advances, 6, https://doi.org/10.1126/sciadv.abc2992, 2020.

Lohmann, U. and Feichter, J.: Global indirect aerosol effects: a review, Atmospheric Chemistry and Physics, 5, 715-737, https://doi.org/10.5194/acp-5-715-2005, publisher: Copernicus GmbH, 2005.

Lohmann, U. and Hoose, C.: Sensitivity studies of different aerosol indirect effects in mixed-phase clouds, Atmospheric Chemistry and Physics, 9, 8917-8934, 2009.

Lohmann, U., Stier, P., Hoose, C., Ferrachat, S., Kloster, S., Roeckner, E., and Zhang, J.: Cloud microphysics and aerosol indirect effects in the global climate model ECHAM5-HAM, Atmos. Chem. Phys., p. 22, 2007.

McMurry, P. H. and Wilson, J. C.: Droplet phase (Heterogeneous) and gas phase (homogeneous) contributions to secondary ambient aerosol formation as functions of relative humidity, Journal of Geophysical Research: Oceans, 88, 5101-5108, https://doi.org/https://doi.org/10.1029/JC088iC09p05101, 1983.

Mertens, M., Jöckel, P., Matthes, S., Nützel, M., Grewe, V., and Sausen, R.: COVID-19 induced lower-tropospheric ozone changes, Environmental Research Letters, 16, 064 005, 2021.

Myhre, G., D.Shindell, Bréon, F.-M., Collins, W., Fuglestvedt, J., Huang, J., Koch, D., Lamarque, J.-F., Lee, D., Mendoza, B., Nakajima, T., Robock, A., Stephens, G., Takemura, T., and Zhang, H.: IPCC AR5, WG1, Chapter 8: Anthropogenic and Natural Radiative Forcing, https://archive.ipcc.ch/pdf/assessment-report/ar5/wg1/WG1AR5_Chapter08_FINAL.pdf, 2013.

Neubauer, D., Ferrachat, S., Siegenthaler-Le Drian, C., Stier, P., Partridge, D. G., Tegen, I., Bey, I., Stanelle, T., Kokkola, H., and Lohmann, U.: The global aerosol-climate model ECHAM6.3-HAM2.3 - Part 2: Cloud evaluation, aerosol radiative forcing, and climate sensitivity, Geoscientific Model Development, 12, 3609-3639, https://doi.org/10.5194/gmd-12-3609-2019, 2019.

Nordeng, T. E.: Exploring the uncertainties in the aviation soot-cirrus effect, ECMWF Tech. Memo., No. $206,1994$.

Petetin, H., Bowdalo, D., Soret, A., Guevara, M., Jorba, O., Serradell, K., and Pérez García-Pando, C.: Meteorology-normalized impact of the COVID-19 lockdown upon $\mathrm{NO}_{2}$ pollution in Spain, Atmospheric Chemistry and Physics, 20, 11 119-11 141, https://doi.org/10.5194/acp20-11119-2020, 2020. 
Platnick, S., Durkee, P. A., Nielsen, K., Taylor, J. P., Tsay, S.-C., King, M. D., Ferek, R. J., Hobbs, P. V., and Rottman, J. W.: The Role of Background Cloud Microphysics in the Radiative Formation of Ship Tracks, Journal of the Atmospheric Sciences, 57, 2607-2624, https://doi.org/10.1175/1520-0469(2000)057<2607:TROBCM>2.0.CO;2, publisher: American Meteorological Society Section: Journal of the Atmospheric Sciences, 2000.

Pozzer, A., Reifenberg, S., Kumar, V., Franco, B., Taraborrelli, D., Gromov, S., Ehrhart, S., Jöckel, P., Sander, R., Fall, V., Rosanka, S., Karydis, V., Akritidis, D., Emmerichs, T., Crippa, M., Guizzardi, D., Kaiser, J. W., Clarisse, L., Kiendler-Scharr, A., Tost, H., and Tsimpidi, A.: Simulation of organics in the atmosphere: evaluation of EMACv2. 54 with the Mainz Organic Mechanism (MOM) coupled to the ORACLE (v1. 0) submodel, Geoscientific Model Development Discussions [preprint], pp. 1-50, 2021.

Pringle, K. J., Tost, H., Message, S., Steil, B., Giannadaki, D., Nenes, A., Fountoukis, C., Stier, P., Vignati, E., and Lelieveld, J.: Description and evaluation of GMXe: a new aerosol submodel for global simulations (v1), Geoscientific Model Development, 3, 391-412, https://doi.org/10.5194/gmd-3-391-2010, 2010.

Pruppacher, H. R. and Klett, J. D.: Microphysics of Clouds and Precipitation, 1997.

Quaas, J., Gryspeerdt, E., Vautard, R., and Boucher, O.: Climate impact of aircraft-induced cirrus assessed from satellite observations before and during COVID-19, Environmental Research Letters, 16, 064 051, 2021.

Righi, M., Hendricks, J., and Beer, C. G.: Exploring the uncertainties in the aviation soot-cirrus effect, Atmospheric Chemistry and Physics Discussions, 2021, 1-31, https://doi.org/10.5194/acp-2021-329, 2021.

Roeckner, E., Brokopf, R., Esch, M., Giorgetta, M., Hagemann, S., Kornblueh, L., Manzini, E., Schlese, U., and Schulzweida, U.: Sensitivity of simulated climate to horizontal and vertical resolution in the ECHAM5 atmosphere model, Journal of Climate, 19, 3771-3791, 2006.

Schumann, U., Baumann, R., Baumgardner, D., Bedka, S. T., Duda, D. P., Freudenthaler, V., Gayet, J.-F., Heymsfield, A. J., Minnis, P., Quante, M., et al.: Properties of individual contrails: a compilation of observations and some comparisons, Atmospheric Chemistry and Physics, 17, 403-438, 2017.

Schumann, U., Bugliaro, L., Dörnbrack, A., Baumann, R., and Voigt, C.: Aviation Contrail Cirrus and Radiative Forcing Over Europe During 6 Months of COVID-19, Geophysical Research Letters, 48, e2021GL092 771, 2021a.

Schumann, U., Poll, I., Teoh, R., Koelle, R., Spinielli, E., Molloy, J., Koudis, G. S., Baumann, R., Bugliaro, L., Stettler, M., and Voigt, C.: Air traffic and contrail changes over Europe during COVID-19: a model study, Atmospheric Chemistry and Physics, 21, 7429-7450, https://doi.org/10.5194/acp-21-7429-2021, 2021 b.

Sicard, P., De Marco, A., Agathokleous, E., Feng, Z., Xu, X., Paoletti, E., Rodriguez, J. J. D., and Calatayud, V.: Amplified ozone pollution in cities during the COVID-19 lockdown, Science of The Total Environment, 735, 139 542, https://doi.org/10.1016/j.scitotenv.2020.139542, 2020 .

Steinbrecht, W., Kubistin, D., Plass-Dülmer, C., Davies, J., Tarasick, D. W., Gathen, P. v. d., Deckelmann, H., Jepsen, N., Kivi, R., Lyall, N., Palm, M., Notholt, J., Kois, B., Oelsner, P., Allaart, M., Piters, A., Gill, M., Van Malderen, R., Delcloo, A. W., Sussmann, R., Mahieu, E., Servais, C., Romanens, G., Stübi, R., Ancellet, G., Godin-Beekmann, S., Yamanouchi, S., Strong, K., Johnson, B., Cullis, P., Petropavlovskikh, I., Hannigan, J. W., Hernandez, J.-L., Rodriguez, A. D., Nakano, T., Chouza, F., Leblanc, T., Torres, C., Garcia, O., Röhling, A. N., Schneider, M., Blumenstock, T., Tully, M., Paton-Walsh, C., Jones, N., Querel, R., Strahan, S., Stauffer, R. M., Thompson, A. M., Inness, A., Engelen, R., Chang, K.-L., and Cooper, O. R.: COVID-19 Crisis Reduces Free Tropospheric Ozone across the Northern Hemisphere, Geophysical Research Letters, n/a, e2020GL091 987, https://doi.org/10.1029/2020GL091987, e2020GL091987 2020GL091987, 2021. 
Tiedtke, M.: A Comprehensive Mass Flux Scheme for Cumulus Parameterization in Large-Scale Models, Monthly Weather Review, 117, 1779-1800, https://doi.org/10.1175/1520-0493(1989)117<1779:ACMFSF>2.0.CO;2, publisher: American Meteorological Society Section: Monthly Weather Review, 1989.

Tobías, A., Carnerero, C., Reche, C., Massagué, J., Via, M., Minguillón, M. C., Auey, A., and Querol, X.: Changes in air quality during the lockdown in Barcelona (Spain) one month into the SARS-CoV-2 epidemic, Science of The Total Environment, 726, 138 540, https://doi.org/10.1016/j.scitotenv.2020.138540, 2020.

Tost, H., Jöckel, P., and Lelieveld, J.: Influence of different convection parameterisations in a GCM, Atmospheric Chemistry and Physics, 6, 5475-5493, https://doi.org/10.5194/acp-6-5475-2006, 2006.

Tsimpidi, A. P., Karydis, V. A., Pozzer, A., Pandis, S. N., and Lelieveld, J.: ORACLE (v1.0): module to simulate the organic aerosol composition and evolution in the atmosphere, Geoscientific Model Development, 7, 3153-3172, https://doi.org/10.5194/gmd-7-3153$2014,2014$.

Twomey, S.: The nuclei of natural cloud formation part II: The supersaturation in natural clouds and the variation of cloud droplet concentration, Geofisica pura e applicata, 43, 243-249, https://doi.org/10.1007/BF01993560, 1959.

Urbanek, B., Groß, S., Wirth, M., Rolf, C., Krämer, M., and Voigt, C.: High depolarization ratios of naturally occurring cirrus clouds near air traffic regions over Europe, Geophysical research letters, 45, 13-166, 2018.

Van Heerwaarden, C. C., Mol, W. B., Veerman, M. A., Benedict, I., Heusinkveld, B. G., Knap, W. H., Kazadzis, S., Kouremeti, N., and Fiedler, S.: Record high solar irradiance in Western Europe during first COVID-19 lockdown largely due to unusual weather, Communications Earth \& Environment, 2, 1-7, 2021.

Venter, Z. S., Aunan, K., Chowdhury, S., and Lelieveld, J.: COVID-19 lockdowns cause global air pollution declines, Proceedings of the National Academy of Sciences, 117, 18 984-18 990, https://doi.org/10.1073/pnas.2006853117, 2020.

550 Voigt, C., Schumann, U., Minikin, A., Abdelmonem, A., Afchine, A., Borrmann, S., Boettcher, M., Buchholz, B., Bugliaro, L., Costa, A., et al.: ML-CIRRUS: The airborne experiment on natural cirrus and contrail cirrus with the high-altitude long-range research aircraft HALO, Bulletin of the American Meteorological Society, 98, 271-288, 2017.

Voigt, C., Lelieveld, J., Schlager, H., Schneider, J., Curtius, J., Meerkötter, R., Sauer, D., Bugliaro, L., Bohn, B., Crowley, J. N., Erbertseder, T., Groß, S., Hahn, V., Li, Q., Mertens, M., Pöhlker, M., Pozzer, A., Schumann, U., Tomsche, L., Williams, J., Zahn, A., Andreae, M., Borrmann, S., Bräuer, T., Dörich, R., Dörnbrack, A., Edtbauer, A., Ernle, L., Fischer, H., Giez, A., Granzin, M., Grewe, V., Harder, H., Heinritzi, M., Holanda, B., Jöckel, P., Kaiser, K., Krüger, O., Lucke, J., Marsing, A., Martin, A., Matthes, S., Pöhlker, C., Pöschl, U., Reifenberg, S., Ringsdorf, A., Scheibe, M., Tadic, I., Zauner-Wieczorek, M., Henke, R., and Rapp, M.: Cleaner sky during the Covid-19 confinement, Bulletin of the American Meteorological Society, submitted, 2021.

Yoon, J., Chang, D., Lelieveld, J., Pozzer, A., Kim, J., and Yum, S.: Empirical evidence of a positive climate forcing of aerosols at elevated albedo, Atmospheric Research, 229, 269-279, 2019. 